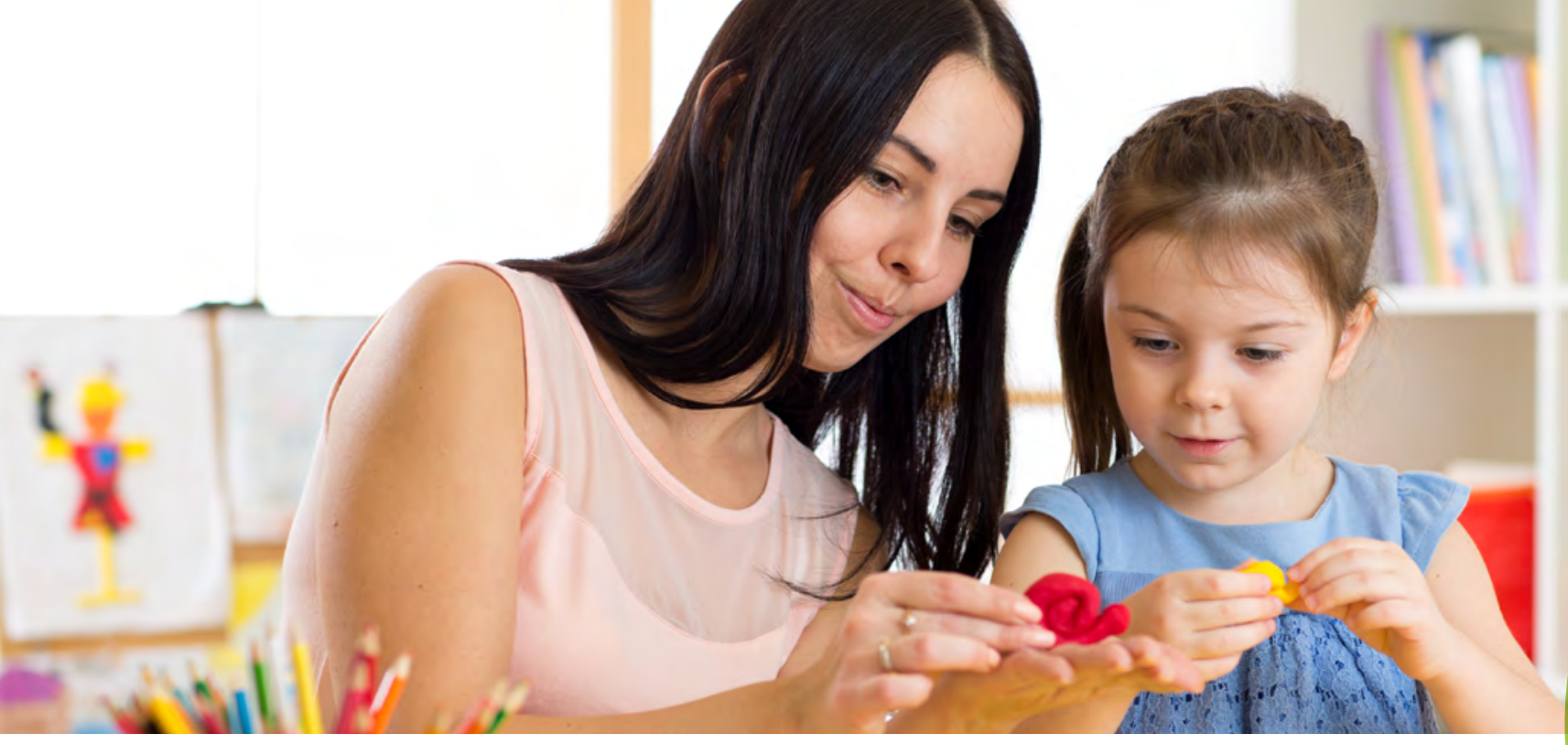

\title{
How much do we really know about 'Theraplay' for young children?
}

By Dr. Jessica Edwards

'Theraplay' is an intervention that aims to enhance attachment, self-esteem and trust in others for children with behavioural, emotional or developmental difficulties. The intervention, founded on attachment theory, ${ }^{1}$ harnesses natural and playful interactions between caregivers and children to develop healthy and positive relationships. Although Theraplay is used worldwide in various settings, its effectiveness is unclear. For this reason, researchers at the University of Lincoln, UK conducted a systematic literature review on the effectiveness of Theraplay for children $<12$ years-of-age and the quality of Theraplay research.

Rebecca Money and colleagues found only seven quantitative studies using Theraplay as a single treatment for children, which were most commonly case series. Within these studies, they found wide variation in the quality of research methodology, as well as in Theraplay practice and evaluation. Although the evidence base was small and limited, Money et al. did find some indication that Theraplay might be helpful for children with internalising or externalising symptoms, dual diagnoses and developmental difficulties, when compared to the same children pre-treatment or a waitlist control group. However, they found less promising evidence to support an effect in looked-after children with social and/or emotional difficulties.

For now, it seems that firm conclusions about Theraplay's effectiveness cannot yet be drawn due to a lack of rigorous research. Money et al. conclude that high quality evaluations of Theraplay and its mechanisms of change are needed to inform the use of this intervention in practice.

\section{Referring to:}

Money, R., Wilde, S. \& Dawson, D. (2020), Review: The effectiveness of Theraplay for children under 12 - a systematic literature review. Child Adolesc. Ment. Health. doi: 10.1111/ camh.12416.

\section{References:}

${ }^{1}$ Bowlby, J. (1973). Attachment and loss. Separation Anxiety and Anger, Vol. 2. London: Hogarth Press.

\section{Glossary:}

Attachment theory: proposes that the child-caregiver relationship established during childhood can influence emotion regulation and other aspects of development; originally by proposed by Bowlby in 1969.

Internalising symptoms: emotional symptoms which tend to be expressed internally, such as anxiety and low mood.

\section{Externalising symptoms: maladaptive} behaviours which are directed externally towards the environment, such as aggressive behaviours and impulsivity.

Theraplay: A child and caregiver therapy for building and enhancing attachment, selfesteem, trust in others, and joyful engagement. It is based on the natural patterns of playful, positive interaction between caregiver and child and is personal, physical and fun. 